\title{
Preservice mathematics teachers' ways of using problem solving strategies while solving mathematical word problems ${ }^{1}$
}

\author{
Neslihan Bulut ${ }^{2}$ \\ Gözdegül Karamık ${ }^{3}$
}

\begin{abstract}
The aim of this study is to investigate the variety of problem solving strategies used by preservice mathematics teachers while solving different mathematical word problems which require representation standards and to identify which strategy is functional for pre-service teachers to apply with middle-school students.

The study was a case study and conducted during the 2009 spring semester. For this study, 150 senior class pre-service teachers of elementary mathematics education were chosen from a public university in Turkey by convenient sampling. Data were collected through an open-ended test developed by researchers. The test was consist of ten mathematical word problems selected from the five sub-learning areas. The test was given to the pre-service teachers and they were asked to solve each problem in different ways. It took 60 minutes for preservice teachers to complete the test. Strategies that pre-service teachers used for solving word problems were categorized by using content analyze. Also interviews were conducted with pre-service teachers in order to identify their opinions about the usability of strategies in middle-school classrooms.

Findings revealed that participants are lack of using different strategies while solving word problems. In general the participants did not apply more than one strategy and they used traditional solving strategies instead of extreme ones. Findings of this study will be a guiding spirit to teacher educators for the enhancement of preservice teacher education programs.
\end{abstract}

Keywords: [Problem solving strategies; mathematical word problems; preservice teacher; problem solving; teacher education]

\footnotetext{
1 This study was presented in Frontiers in Science Education Research Conference (2009)

${ }^{2}$ Assistant Professor Doctor, Gazi University, Faculty of Education, Elementary Mathematics Education, mrsbulut@gmail.com

${ }^{3}$ Research Assistant, Gazi University, Faculty of Education, Elementary Mathematics Education, gozdearik@gmail.com
} 
Bulut, N., \& Karamık, G. (2015). Preservice mathematics teachers' ways of using problem solving strategies while solving mathematical word problems. International Journal of Human Sciences, 12(2), 1180-1191. doi:10.14687/ijhs.v12i2.3420

\section{Introduction}

"We believe that if we want students to understand mathematics, it is more belpful to think of understanding as something that results from solving problems, rather than something we can teach directly" (Hiebert, 1997, p.25).

Virtually many students are unaware of it, mathematics is a great part of our lives. In numerous fields problem solving become crucial for students. Beyond using problem solving only in mathematics, students learn how to solve problems that they encounter in real life. In the event of realizing different problem solving strategies they can canalize this to other lessons and also to their real life.

Posamentier and Krulik (1998) defined problem as a situation that a person can meet, which requires resolution, and also the path to the solution, is not known immediately. In Agenda for Action NCTM stated that, problem solving must be the focus of school mathematics (NCTM, 1980, p.1). Emphasize on problem solving was continued with Curriculum and Evaluation Standards for School Mathematics. The mathematics instruction will aim to make students suitably skilled problem solvers. Making students familiar to different problem solving strategies and allowing them to practice these strategies is one of the important goals in mathematics education. Problem solving is seem to have a critical role in a good instructional program (NCTM, 1989).

According to Ausubel (1979) children learn subject matter within the meaningful learning. Instructors role is to present the information in a written or verbal way. After the presentation of the information, students meaninfully learn the subjet matter by interiorising it. Therefore, it is necessary for teachers to assist students while executing the meaningful learning.

Although still teachers are reflective and considerate; teaching is cognitively compelling process comprising problem solving and decision making. In consequence, teachers knowledge should be a primary variable in the study of teaching (Carpenter, et al.; 1988).

Posamentier and Krulik (1998) associated the main handicap of the successful problem solving in mathematics curriculum with the weakness of teachers' problem solving training. With respect to his views, teachers receive a defective training of problem solving strategies and also, they are not able to combine the problem solving skills with their regular teaching problems. Teachers need to be aware of different representations of problems for encouraging their students. Posamentier and Krulik (1998, p.3) stated that, problem solving can be thought of in three different ways:

1) Problem solving is a subject for study in and of itself,

2) Problem solving is an approach to a particular problem,

3) Problem solving as a way of teaching.

He concluded that, teachers' problem solving ability has an integral part in teaching. Firstly, teachers should know which problem solving strategies are available for a problem, then, when and how to use them. Also, not only mathematical problems but daily life experiences require different strategies. Every teacher, who aims to make students skillful problem solvers, should have a collection of strategies.

Strategies for solving problems are identifiable methods of approaching a task that are completely independent of the specific topic or subject matter. Strategy goals play a part in all phases of problem solving: understanding the problem, solving the problem and reflecting on the answer and solutions. Strategy and process goals are;

- Develop problem analysis skills-to improve students' ability to analyze an unfamiliar problem, identify wanted and needed information, ignore nonessential information and clearly state the goal of the problem. 
Bulut, N., \& Karamık, G. (2015). Preservice mathematics teachers' ways of using problem solving strategies while solving mathematical word problems. International Journal of Human Sciences, 12(2), 1180-1191. doi:10.14687/ijhs.v12i2.3420

- Develop and select strategies- to help students acquire a collection of problem solving strategies that are useful in a variety of problem solving settings and to select and use those strategies appropriately

- Justify solutions-to improve students' ability to assess the validity of answers

- Extend or generalize problems-to help students learn to go beyond the solution to problems; to consider results or processes applied in other situations or used to form rules or general procedures (Van de Walle, 2004, p.54).

Posamentier and Krulik (1998) make a conscious effort to label the strategies and to use these labels as much as possible. These strategies are "working backwards", "finding patterns", "adopting a different point of view", "solving a simpler, analogous problem", "considering extreme cases", "making a drawing", "intelligent guessing and testing", "accounting for all possibilities", "organizing data" and "logical reasoning".

Standards are descriptions of what mathematics instruction should enable students to know and do. They specify the understanding, knowledge, and skills that students should acquire from prekindergarten through grade 12. The Content Standards-Number and Operations, Algebra, Geometry, Measurement, and Data Analysis and Probability-explicitly describe the content that students should learn. The Process Standards-Problem Solving, Reasoning and Proof, Communication, Connections, and Representation - highlight ways of acquiring and using content knowledge (NCTM, 2000, p.30). Instructional programs from prekindergarten through grade 12 should enable all students to,

- create and use representations to organize, record, and communicate mathematical ideas

- select, apply, and translate among mathematical representations to solve problems;

- use representations to model and interpret physical, social, and mathematical phenomena (NCTM, 2000,p. 67).

Representations should be treated as essential elements in supporting students' understanding of mathematical concepts and relationships; in communicating mathematical approaches, arguments, and understandings to one's self and to others; in recognizing connections among related mathematical concepts; and in applying mathematics to realistic problem situations through modeling (NCTM, 2000, p.67).

NCTM standards (2000) consider it necessary to force students for developing and applying new problem solving strategies. When viewed from this aspect the role of the teacher is evaluating the students' conceptions and usage of problem solving strategies.

\section{Purpose of the study}

The present study aimed investigate the variety of problem solving strategies used by preservice mathematics teachers while solving different mathematical word problems which require representation standards and to identify which strategy is functional for pre-service teachers to apply with middle-school students. With this purpose in mind the study focused on the following questions:

1) What do pre-service mathematics teachers know about the diversity of strategies for solving different mathematical word problems?

2) Which problem solving strategies do they prefer for their middle school students as coherent ways? 
Bulut, N., \& Karamık, G. (2015). Preservice mathematics teachers' ways of using problem solving strategies while solving mathematical word problems. International Journal of Human Sciences, 12(2), 1180-1191. doi:10.14687/ijhs.v12i2.3420

\section{Method}

\subsection{Type of the study}

The study was a case study. Case study includes probing a case, situation, social group or setting (Mcmillan,2000). In this study preservice mathematics teachers' usage of problem solving strategies while solving word problems were investigated intimately.

\subsection{Participants}

Sampling of this study was constituted with convenient sampling. Participants were 150 senior class pre-service mathematics teachers (PSMTs) of an education faculty in a public university in a metropolitan in Turkey. The study was conducted during 2009 spring semester.

\subsection{Data Collection}

Data were collected through an open-ended test developed by researchers. The test was consist of ten mathematical word problems. These ten questions which require representation standards were adapted from the Posamentier and Krulik's (1998) work and Turkish Ministry of Education elementary mathematics curriculum (MONE, 2006). The adapted ten questions were administered to the PSMTs. Questions were selected with respect to the five sub-learning areas (numbers, geometry, algebra, measurement, statistics and probability). Adapted questions were given to 150 senior class pre-service teachers of Primary Mathematics Education Department of a public university. For measuring the PSMTs' knowledge of problem solving strategies PSMTs were asked to solve mathematical word problems. During the implementation of the test researchers emphasized using different strategies for solving every question and to think which strategy is useful for teaching middle school students. One hour time was given to the PSMTs to solve questions. The questions were solved by PSMTs in different ways.

\subsection{Evaluation of data}

Researchers categorized solutions of PSMTs by using content analyze. A central idea in content analysis is that the many words of the text part classified into much fewer content categories (Weber, 1990, p. 12). In this research the analyze unit is the pre-service teachers' strategies for each question. After the strategies of the PSMTs were categorized, frequency for each category was calculated. The frequencies are shown in tables (Table 1.1, 1.2, 1.3, 1.4, 1.5, 1.6, 1.7, 1.8, 1.9 and 1.10).

For reliability and validity, the analyze units was examined by 3 mathematics educators. At the beginning of the study researchers planned to interview with participants who use extreme strategies. However PSMTs were lack of finding extreme strategies for all questions, interviews were conducted with randomly selected 6 pre-service mathematics teachers. Researchers asked to the selected PSMTs the following question: "Which strategy is useful for applying with middle school students and why do you chose this strategy? Some examples of the interview responses of PSMTs were given under the solutions in some cases.

\section{Results}

In this section PSMTs' responses to each question was examined separately in different cases. In some cases interview transcripts of PSMTs were given.

\section{Case 1}

Problem 1. In a room with 5 people; Kaan, Irmak, Defne, Kerem and Mahmut shakes hands with everybody else exactly once. How many handshakes are there? 
Bulut, N., \& Karamık, G. (2015). Preservice mathematics teachers' ways of using problem solving strategies while solving mathematical word problems. International Journal of Human Sciences, 12(2), 1180-1191. doi:10.14687/ijhs.v12i2.3420

In the first question, pre-service teachers used 9 alternative solution strategies. As shown in Table 1.1, first solution which called "visual representation strategy" was used by 86 percent of the pre-service teachers. Solution of a participant for this was given in Figure 1. "W" indicates the wrong responses of participants.

Table 1

Frequencies for problem 1.

\begin{tabular}{llllllllllll}
\hline Strategies & 1 & 2 & 3 & 4 & 5 & 6 & 7 & 8 & 9 & 10 & W \\
\hline Frequencies & 129 & 6 & 17 & 0 & 3 & 4 & 45 & 1 & 1 & 1 & 22 \\
\hline
\end{tabular}

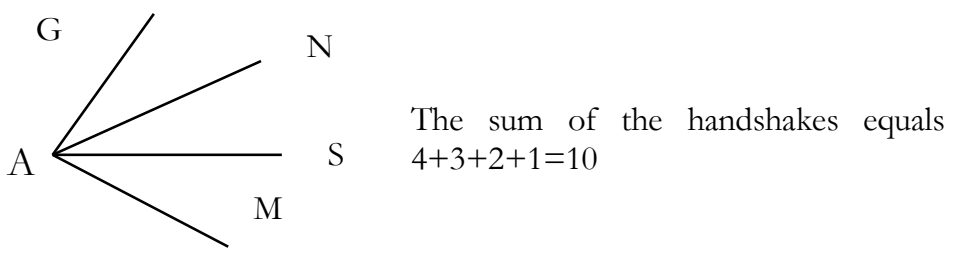

Figure 1. A participant's solution for Problem 1.

The second strategy, which was called as "accounting for all possibilities", used by 4 percent of the pre-service teachers. Solution of a participant for this was given in Figure 2.

\begin{tabular}{|c|c|c|c|c|c|}
\hline & A & $\mathrm{S}$ & $\mathrm{G}$ & $\mathrm{M}$ & $\mathrm{N}$ \\
\hline $\mathrm{A}$ & $\mathrm{X}$ & & & & \\
\hline $\mathrm{Y}$ & & X & & & \\
\hline $\mathrm{S}$ & & & $\mathrm{X}$ & & \\
\hline $\mathrm{M}$ & & & & $\mathrm{X}$ & \\
\hline $\mathrm{G}$ & & & & & X \\
\hline
\end{tabular}

$$
\frac{n \cdot(n-1)}{2}=\frac{5.4}{2}=10
$$

Figure 2. A participant's solution

The third strategy was used by 11 percent of the pre-service teachers, they "adopt a different point of view". Solution of a participant for this was given below;

The room with five people, each of whom will shake four other people's hands. 5.4=20 but we must divide by 2 to eliminate the duplication so $\frac{20}{2}=10$.

The fourth strategy is "looking for a pattern". None of the PSMTs used this strategy. The fifth one is "organizing data" and 2 percent of pre-service teachers used it. Solution of a participant for fifth strategy was shown in Figure 3.

\begin{tabular}{llllll}
\hline Organizing Data & & & & & \\
\hline Number of People & 5 & 4 & 3 & 2 & 1 \\
\hline Number of Handshakes & 4 & 3 & 2 & 1 & 0 \\
\hline
\end{tabular}

The sum of handshakes is 10 .

Figure 3. A participant's solution 
Bulut, N., \& Karamik, G. (2015). Preservice mathematics teachers' ways of using problem solving strategies while solving mathematical word problems. International Journal of Human Sciences, 12(2), 1180-1191. doi:10.14687/ijhs.v12i2.3420

The sixth strategy is a combination of "solving a simpler problem with visual representation, organizing data, and looking for a pattern". If we combine this, it becomes a geometry problem, in which the answer is the number of sides and diagonals of an "n-gon". 3 percent of pre-service teachers used this strategy. Solution of a participant for this was shown in Figure 4.

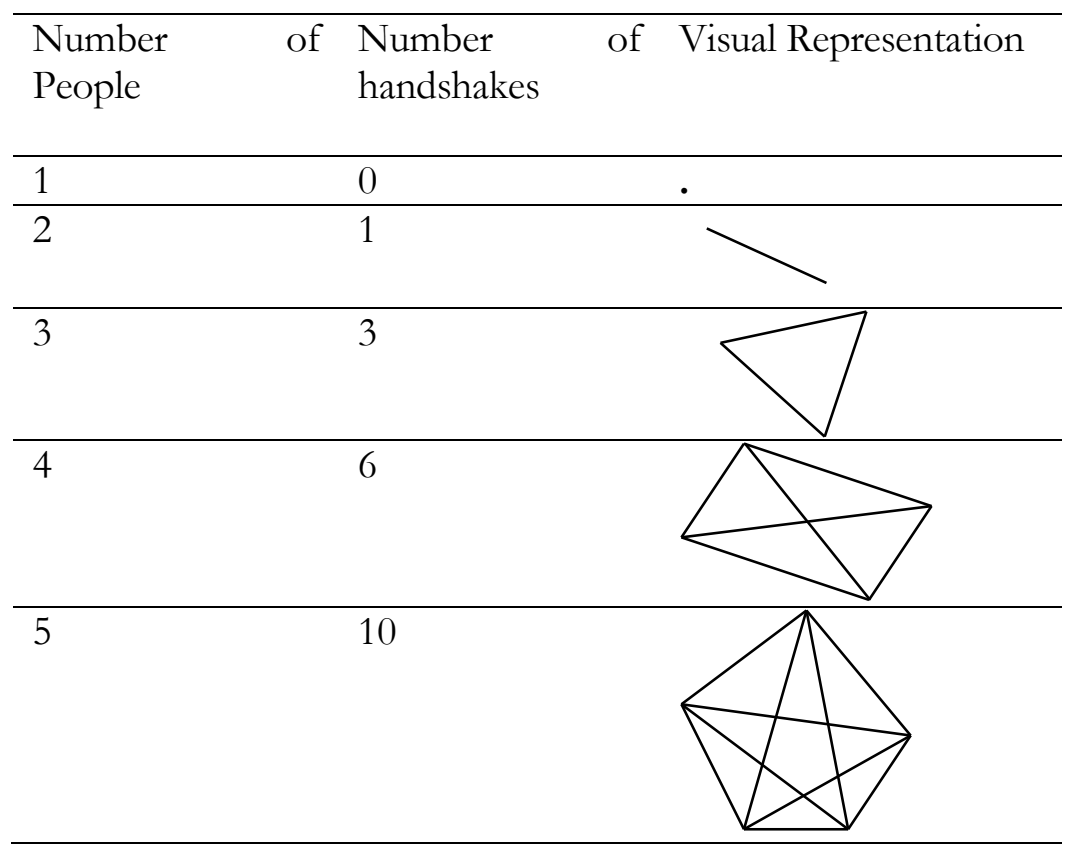

Figure 4. A participant's solution

$d=\frac{n \cdot(n-3)}{2}$, wheren $>3$

$d=\frac{5.2}{2}=5$ Number of diagonals,

$5+5=10$ total handshakes.

The seventh one is using combinations formula and 30 percent of the participants used the strategy.

Solution of a participant for this was given below;

${ }_{5} C_{2}=\frac{5.4}{2}=10$

The eighth strategy includes a combination of accounting for all the possibilities and visual representation. The ninth strategy shows Cartesian multiplication of clusters. The tenth strategy combines adopting a different point of view and visual representation.

The following was an interview transcript of a PSMT.

$\mathrm{T}$ : Yes Can, in the first question which strategies did you use?

C: I used visual representation, combination formula and also the other.

T: The other?

C: I wrote all people's names than below the names I wrote who had shaken hands. I found 20 handshakes. But I noticed there are same handshakes. I remove them and find 10.

T: Which strategy is useful to apply with your middle school students?

C: I think the first one, visual representation. 
Bulut, N., \& Karamık, G. (2015). Preservice mathematics teachers' ways of using problem solving strategies while solving mathematical word problems. International Journal of Human Sciences, 12(2), 1180-1191. doi:10.14687/ijhs.v12i2.3420

T: Why?

C: As I remember, curriculum suggests using visual representations firstly. In the beginning of the lesson I use visual representations because students can understand them easily. Then I ask this question which contains more people. And I ask them how to solve this. Then I say we need a formula and give combination formula and also remind them to use this in tests for being quick.

\section{Case 2}

Problem 2. Sertaç was racing in a bike marathon. He was $3 / 8$ of the way across a narrow bridge, when he heard the whistle of a train approaching the bridge from behind him at $60 \mathrm{~km}$ per hour. Being an amateur mathematician as well as a marathon biker, Sertaç calculated that he could just reach either end of the bridge at the same time as the train. How fast was Sertaç pedaling his bike?

Table 2

Frequencies for problem 2

\begin{tabular}{lllll}
\hline Strategies & 1 & 2 & 3 & W \\
\hline Frequencies & 94 & 68 & 2 & 23 \\
\hline
\end{tabular}

In this case, 62 percent of the participants solved the second question by "solving a simpler analogous problem" strategy. The second strategy called "another point of view" used by 45 percent of the pre-service teachers. In the third solution 1 percent of the pre-service teachers applied "logical reasoning". Also 15 percent was not able to find the correct answer. The following was an interview transcript of a PSMT.

T: Yes Burcu, for this problem which strategy is useful to apply with your primary grade students? Why?

B: I'm good at using formulas. We learned like this and also I use this in my lessons.

T: Can you say the teachers' experiences are important to select the strategy?

B: I think....for example I do like this.

\section{Case 3}

Problem 3. Granddad İsmail has a square shaped land. He wants to build a triangle shaped barn. Two corners of the triangle should stand on the midpoints of the sides of the square. What is the ration of the area of the triangle to the area of the square?

Table 3

Frequencies for problem 3

\begin{tabular}{llrrrr}
\hline Strategies & 1 & 2 & 3 & 4 & W \\
\hline Frequencies & 85 & 16 & 48 & 27 & 38 \\
\hline
\end{tabular}

The third question is a geometry problem. In the first strategy 57 percent of the pre-service teachers used only "algebraic formulas". The second strategy is "simpler analogous problem" and 11 percent of the pre-service teachers used solving a simpler analogous problem strategy. The third one is "another point of view" strategy, and it is used by 32 percent of the pre-service teachers. The 
Bulut, N., \& Karamık, G. (2015). Preservice mathematics teachers' ways of using problem solving strategies while solving mathematical word problems. International Journal of Human Sciences, 12(2), 1180-1191. doi:10.14687/ijhs.v12i2.3420

fourth one is a "visual representation" involving Pisagor theorem and used by 18 percent of the pre-service teachers.

\section{Case 4}

Problem 4. Serap has a birthday party and her friends Mehtap, Ali and Harun wants to buy a gift for her. There exists 3 kinds of t-shirts and 4 kinds of skirts. If her friends wants to buy a t-shirt and a skirt, how many possible alternatives they have?

Table 4

Frequencies for problem 4

\begin{tabular}{lllll}
\hline Strategies & 1 & 2 & 3 & $\mathrm{~W}$ \\
\hline Frequencies & 43 & 88 & 57 & 21 \\
\hline
\end{tabular}

The fourth question's first strategy is using the visual representation by combining with the basic principle of multiplication and 29 percent of the participants applied this strategy. The second strategy is used by 59 percent of the pre-service teachers which is including the combination formula. The third strategy is a combination of visual representation and organizing data. 38 percent of the pre-service teachers applied this strategy.

\section{Case 5}

Problem 5. A shepherd has 425 sheep and 35 goats. Ayşe wants to calculate the numbers of his animals by using a calculator. Unfortunately the key " 5 " is out of order. Describe the ways that she should use to find the correct answer.

Table 5

Frequencies for problem 5

\begin{tabular}{lll}
\hline Strategies & 1 & W \\
\hline Frequencies & 144 & 6 \\
\hline
\end{tabular}

The fifth question was including one strategy. This strategy includes different approaches. Each of these approaches doesn't mean a different strategy. We tried to find if participants are aware of this. Findings revealed that pre-service teachers used different approaches as different strategies. In the interviews they noticed that different approaches do not mean different strategies.

\section{Case 6}

Problem 6. Damla and Semih are both part time workers in the local pizza shop. The shop is open seven days a week. Damla works one day and then has two days off before she works again. Semih works one day, and then has three days off before he works again. Damla and Semih both worked on Tuesday, July 1st. On which other days in July do Damla and Semih work together? 
Bulut, N., \& Karamik, G. (2015). Preservice mathematics teachers' ways of using problem solving strategies while solving mathematical word problems. International Journal of Human Sciences, 12(2), 1180-1191. doi: $10.14687 /$ ijhs.v12i2.3420

Table 6

Frequencies for problem 6

\begin{tabular}{ccccc}
\hline Strategies & 1 & 2 & 3 & $\mathrm{~W}$ \\
\hline Frequencies & 65 & 25 & 83 & 32 \\
\hline
\end{tabular}

In the sixth question 43 percent of the pre-service teachers made a pair of lists. The second strategy is using a visual representation, for example a calendar. 17 percent of the pre-service teachers used this strategy. The last strategy is another point of view including their common multiple and 55 percent of the pre-service teachers used this. The following was an interview transcript of a PSMT.

T: Yes Ada, in this question how many strategies did you use? Which strategy is useful to apply with your primary grade students?

A: I use three strategies. When I solve by first strategy, I think that students will not solve in this way. If they have a calendar they will. And drawing a calendar is more visual. And I use this for a month only. If I need the second month I don't use this strategy. I use the third one. And I want in exams to use the strategy which I use in lessons.

\section{Case 7}

Problem 7. Ali is owing $12 \mathrm{TL}$ to Ahmet. If he pays 4 TL of his debt, what is his remaining debt?

Table 7

Frequencies for problem 7

\begin{tabular}{llll}
\hline Strategies & 1 & 2 & W \\
\hline Frequencies & 31 & 145 & 5 \\
\hline
\end{tabular}

In the seventh question 20 percent of the pre-service teachers used visual representations, 97 percent of the pre-service teachers used algebraic formulas. We paid attention to the problem, this problem was chosen from elementary mathematics curriculum and pre-service teachers were aware of the solution strategies. Findings revealed that, giving a perspective of different strategies will be helpful for pre-service teachers.

\section{Case 8}

Problem 8. Two tests each contain 25 different questions. If the first 5 questions on Test $\mathrm{A}$ are added to the end of Test $\mathrm{B}$, and the first 5 questions on Test $\mathrm{B}$ are added to the end of Test $\mathrm{A}$, each test now has 30 questions. How many questions will be the same on both tests, assuming they began with no questions in common?

Table 8

Frequencies for problem 8

\begin{tabular}{lccccc}
\hline Strategies & 1 & 2 & 3 & 4 & W \\
\hline Frequencies & 58 & 57 & 53 & 8 & 15 \\
\hline
\end{tabular}


Bulut, N., \& Karamik, G. (2015). Preservice mathematics teachers' ways of using problem solving strategies while solving mathematical word problems. International Journal of Human Sciences, 12(2), 1180-1191. doi:10.14687/ijhs.v12i2.3420

In the eight question 39 percent of the pre-service teachers used organizing data strategy. 38 percent of the pre-service teachers used visual representation. 35 percent of the pre-service teachers used algebraic formula. 5 percent of the pre-service teachers used a combination of visual representation and solving simpler analogous problem strategies.

\section{Case 9}

Problem 9. The two spinners shown below are spun, and the resulting numbers are added. What is the probability that the sum of the two numbers is even?
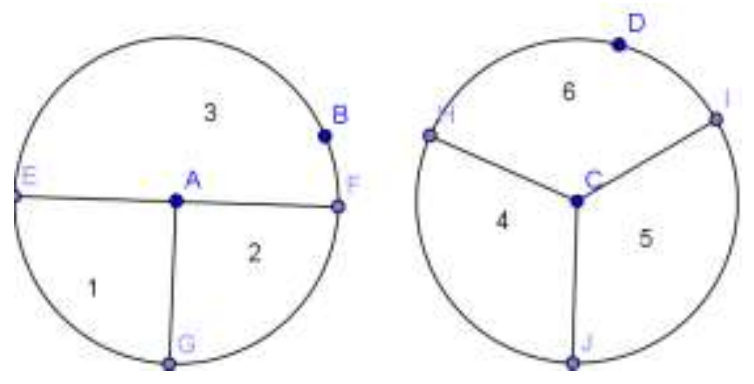

Table 9

Frequencies for problem 9

\begin{tabular}{llll}
\hline Strategies & 1 & 2 & W \\
\hline Frequencies & 70 & 134 & 15 \\
\hline
\end{tabular}

The ninth question is a permutation question. The first strategy includes the formula. Preservice teachers who are familiar with probability solved this in the manner; $\mathrm{P}(3+5)+\mathrm{P}(1+5)+$ $\mathrm{P}(2+4)+\mathrm{P}(2+6)$. Nobody solve this question using the second strategy. We can look this problem from a different point of view. The probabilities of getting an odd number on the left spinner and an odd number on the right hand spinner (and two evens) are not done by them. The third strategy is accounting for all possibilities by setting up an organized sample space. An interesting point is very huge percent $(\% 86)$ couldn't solve the question or solve incorrect. When we look at the problem, probability of each number was not equal on the first spinner. Most of the participants did not pay attention to this point. Because they overlook the first spinner has four equal regions.

\section{Case 10}

Problem 10. Mustafa has 10 coins of 1TL. Each coin has $0,5 \mathrm{~cm}$ thickness and $1 \mathrm{~cm}$ Radius. $\mathrm{He}$ wants to form a perpendicular circular cylinder by putting each coin over and over. What is the volume of this perpendicular circular cylinder?

Table 10

Frequencies for problem 10

\begin{tabular}{lllll}
\hline Strategies & 1 & 2 & 3 & W \\
\hline Frequencies & 20 & 0 & 6 & 129 \\
\hline
\end{tabular}


Bulut, N., \& Karamık, G. (2015). Preservice mathematics teachers' ways of using problem solving strategies while solving mathematical word problems. International Journal of Human Sciences, 12(2), 1180-1191. doi:10.14687/ijhs.v12i2.3420

The last one is a geometry problem. In the first strategy 46 percent of pre-service teachers find volume of a cylinder then multiply it with ten. In the second strategy 89 percent of pre-service teachers find height of ten cylinders then find volume. In general the pre-service teachers use both of the strategies. But no one use another strategy. The following was an interview transcript of a PSMT.

T: Yes Ahmet, in this question how many strategies did you use?

A: Two

T: Which strategy is useful to apply with your middle school students?

A: I think it is same. I can use both of them

T: Why?

A: It is not same but same....If we use a representation they can see two drawings are same only different is process.

T: Process?

A: The operations, algebraic operations are different. If I have to choose one I will choose the second one because of operations. It is shorter than the first.

\section{Discussion}

Findings were revealed that participant pre-service teachers are lack of using strategies. Their usage of problem solving strategies are restricted with the most known strategy. In general the participant pre-service mathematics teachers do not apply more than one strategy and they use traditional strategies instead of extreme strategies. Participants mostly use visual representation strategy and algebraic formulas. As NCTM (2000) stated that teaching different representations is an essential element in supporting students' understanding of mathematical concepts and relationships, teachers and teacher candidates should be well equipped about different representations. Teachers' and teacher candidates' repertory of problem solving strategies will contribute to the teaching of different representations. Interview results showed that participant preservice teachers chose the traditional strategies while solving word problems because of the following reasons:

- Curriculum,

- Operational Simplicity,

- $\quad$ Time for solving,

- Complexity of problem,

- Level of the class,

- Experiences of teachers,

- Beliefs of teachers,

- Ability of teachers,

- Type of the exam(open-ended or multiple choice)

- If the numbers in the problem are small, they use visual representation but if the numbers are big they use formulas.

- If they don't remember the formula for the questions they use other strategies.

\subsection{Usability of Study Results}

Findings of this study will contribute to the teacher education programs. Since the study is a case study, it executes a necessity in the field of teacher preparation. Preservice mathematics teachers need to be well prepared on problem solving strategies for reflecting their knowledge to pupils. During the pedagogic content courses in-depth analysis of problem solving strategies will be 
Bulut, N., \& Karamık, G. (2015). Preservice mathematics teachers' ways of using problem solving strategies while solving mathematical word problems. International Journal of Human Sciences, 12(2), 1180-1191. doi: $10.14687 /$ ijhs.v12i2.3420

carried out. By this way preservice mathematics teachers repertory of different problem solving strategies will be improved. Teachers' possession of extensive repertory on problem solving strategies will make middle school students' learning process convenient.

\section{References}

Ausubel, D. P. (1979). The facilitation of meaningful verbal learning in the classroom. Educational Psychologist, 11, 162-178.

Carpenter, T. P., Fennema, E., Peterson, P. L. and Carey, D. A. (1988). Teachers' Pedagogical Content Knowledge of Students' Problem Solving in Elementary Arithmetic. Journal for Research in Mathematics Education, 19 (5), 385-401.

Hiebert, J., Carpenter, T. P., Fennema, E., Fuson, K., Human, P., Murray, H., Olivier, A., \& Wearne, D. (1997). Making mathematics problematic: A rejoinder to Prawat and Smith. Educational Researcher, 26 (2). 24-26.

McMillan, J. H. (2000). Educational Research: Fundamentals for the Consumer. New York: Longman.

Ministry of National Education (MONE) (2006). İlköğretim Matematik Dersi Öğretim Programı ve Kılavuzu 6-8. Sinıflar. Ankara: Devlet Kitapları Müdürlüğü.

National Council of Teachers of Mathematics [NCTM] (1980). An Agenda for Action: Recommendations for School Mathematics of the 1980s. Reston, VA: Author.

National Council of Teachers of Mathematics [NCTM] (1989). Curriculum and Evaluation Standards for School Mathematics. Reston, VA: Author.

National Council of Teachers of Mathematics [NCTM] (2000). Principle and Standards for School Mathematics. Reston, VA: Author.

Posamentier, A. S. and Krulik, S. (1998). Problem-solving Strategies for Efficient and Elegant Solutions. California: Corwin Press.

Van de Walle, J. A. (2004). Elementary and Middle School Mathematics. Pearson, USA.

Weber, R. P. (1990). Basic Content Analysis (No: 49). Sage. 